\title{
Analysis of gene expression patterns by microarray hybridization in blood mononuclear cells of SLA-DRB I defined Canadian Yorkshire
} pigs

\author{
Maria I Nino-Soto ${ }^{1}$, Razi Jafari Jozani ${ }^{2}$, Byram Bridle ${ }^{1}$ and \\ Bonnie A Mallard*1
}

Address: ${ }^{1}$ Department of Pathobiology, Ontario Veterinary College, University of Guelph, Guelph, Ont., N1G 2W1, Canada and ${ }^{2}$ Faculty of Veterinary Medicine, University of Tehran, Tehran, Iran

Email: Maria I Nino-Soto - mnino@uoguelph.ca; Razi Jafari Jozani - razi_allah@yahoo.com; Byram Bridle - bridleb@mcmaster.ca; Bonnie A Mallard* - bmallard@uoguelph.ca

* Corresponding author

Published: 23 June 2008

BMC Research Notes 2008, I:31 doi:10.1 186/1756-0500-I-31
Received: 10 April 2008

Accepted: 23 June 2008

This article is available from: http://www.biomedcentral.com/1756-0500/I/3I

(c) 2008 Nino-Sotol et al; licensee BioMed Central Ltd.

This is an Open Access article distributed under the terms of the Creative Commons Attribution License (http://creativecommons.org/licenses/by/2.0), which permits unrestricted use, distribution, and reproduction in any medium, provided the original work is properly cited.

\begin{abstract}
Background: The Swine Leukocyte Antigen (SLA) system encodes molecules for self-nonself discrimination and is associated with immune responses and disease resistance. Three lines of pigs defined by their SLA-DRBI alleles were developed at the University of Guelph for xenotransplantation and immune response studies. The aim of this project was to explore the potential association between defined SLA-DRBI alleles and gene transcriptional patterns of other immune-related genes in blood mononuclear cells.

Findings: Three SLA-DRBI alleles were characterized using a RT-PCR-based sequencing method. The loci represented included a new allele, $\mathrm{DRBI} * 04 \mathrm{~ns} \mathrm{OI}$. Next, microarray heterologous (bovineporcine) hybridization together with GPCR were used to explore differential gene expression between SLA-DRBI-defined groups. Microarray analysis showed significant $(p<0.01)$ differential expression for 5 genes, mostly related to inflammation. Genes varied according to the comparison analyzed. Further testing with QPCR revealed the same trend of differential expression for 4 of the genes, although statistical significance was reached for only one.

Conclusion: A new SLA-DRBI allele was characterized. A potential association was found between SLA-DRBI alleles and inflammation-related genes. However, the influence of other genes cannot be ruled out. These preliminary findings agree with other studies linking MHC haplotypes and inflammation processes, including autoimmune disease. The study provides an initial view of the biological interactions between the SLA complex and other immune-related genes. Future studies will focus on characterization of SLA-haplotypes associated with these particular alleles and the dynamics of the immune response to antigenic challenges.
\end{abstract}

\section{Findings}

The highly polymorphic MHC-encoded molecules are crucial for self-nonself discrimination in vertebrates. They constitute the major barrier for transplantation, contain numerous genes involved in immunological and nonimmunological functions and are associated with resist- 
ance or susceptibility to various diseases. The two main classes, I and II, are involved in antigen presentation to Tcells. However, a large number of the genes in the MHC, like class III genes, are not directly related to this function [1,2]. A total of 152 loci have been annotated within this region. In pigs, known as the SLA, the DRB genes show extensive polymorphism in exon 2 and the 135 available sequences identified to date are distributed into at least 10 confirmed allele groups [3].

Different SLA haplotypes have been associated with variation in immune response and disease, as well as reproduction and production traits [4]. Therefore, SLA-defined pigs constitute an invaluable resource to study immune response, disease resistance and production traits, as well as an important large animal model for biomedical research $[5,6]$. Three lines of commercial Yorkshire pigs with defined SLA-DRB1 genotypes were produced at the University of Guelph for xenotransplantation and immune response research $[7,8]$. The aims of this study were to characterize the SLA-DRB1 alleles in these three pig lines and explore differential transcriptional activity between the three groups using heterologous (bovine probes - porcine targets) cDNA microarray and qPCR.

\section{Animals and samples}

Animal use was approved by the Animal Care Committee of the University of Guelph. Thirty-five pigs were included in the study ( $n=6$ for microarray analysis and $n=29$ for qPCR). Pigs came from crossings of an outbred population selected for only by specific SLA-DRB1 alleles. Age of pigs ranged between 3-6 months and all pigs were in good general health at the time of sampling. Venous blood was collected in EDTA coated BD Vacutainer ${ }^{\circledR}$ collection tubes (BD - Canada, Oakville, ON, Canada) and processed immediately after collection. MNCs were isolated using Histopaque-1077 (Sigma-Aldrich Canada Ltd., Oakville, ON, Canada) and total RNA was extracted using TRIzol ${ }^{\mathrm{TM}}$ reagent (Invitrogen Canada Inc., Burlington, ON, Canada). Total RNA was treated with DNA-free (Ambion Inc., TX, USA) to eliminate genomic DNA contamination. Concentration and quality were assessed with an Agilent 2100 Bioanalyzer (Agilent Technologies Inc., Santa Clara, CA, USA).

\section{SLA-DRB I alleles characterization}

The SLA-DRB1 alleles were characterized according to Ho et al. (2006). Briefly, total RNA was reverse transcribed with the ThermoScript ${ }^{\mathrm{TM}}$ RT-PCR system using oligo $\mathrm{d}(\mathrm{T})$ primers (Invitrogen). A specific SLA-DRB1 coding region was amplified with PfuUltra ${ }^{\mathrm{TM}}$ Hotstart High-Fidelity DNA Polymerase (Stratagene, La Jolla, CA, USA) using a final concentration of $3 \mathrm{mM}$ of $\mathrm{MgCl}_{2}$ and annealing temperature at $55^{\circ} \mathrm{C}$. PCR products were gel-extracted with the QIAquick Gel Extraction Kit (Qiagen, Mississauga, ON,
Canada) and purified PCR products were cloned using the Zero Blunt ${ }^{\circledast} \mathrm{TOPO}^{\circledast} \mathrm{PCR}$ cloning kit (Invitrogen). At least 7 colonies per animals were sent for sequencing. Each allele was characterized by sequencing using both forward and reverse primers, from at least two pigs per litter. The complete coding sequence was obtained by overlapping the forward and reverse fragments. Comparison with currently available sequences (GenBank and EBI-IPD-MHC, SLA section databases) was performed using BLAST [9] and ClustalW [10]. Two lines carried the SLA-DRB1*0502 and SLA-DRB $1{ }^{*} 0701$ alleles respectively (Smith et al, 2005 ) as determined by a $100 \%$ homology between the sequences obtained from test samples and the corresponding published sequences. The third line had a novel allele, differing in one bp at position +118 in exon 2 with SLA-DRB $1 * 0403$. This difference corresponds to a point mutation substituting a cytosine for a guanine, which translates in the substitution of an arginine for a glycine residue in the protein encoded by this new allele (Figure 1). Sequences were submitted to GenBank [Genbank:

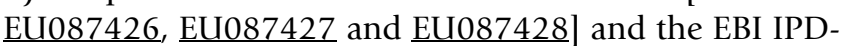
MHC (SLA section) which resulted in the assignment of the SLA-DRB1*04ns01 provisional name to the new allele, approved by the MHC Nomenclature Committee.

\section{cDNA Microarray experiments}

Complete and detailed information on microarray experimental protocols, the datasets and the platform were submitted to GEO (accession number GSE7908). Experiments are described according to the MIAME standard [11]. Heterologous hybridizations (bovine probes porcine targets) were performed to compare the three groups representing defined SLA-DRB1 alleles $(\mathrm{n}=2$ pigs per group). A loop design was used for reciprocal comparisons. Six comparisons with dye-swap on the same slide were performed for a total of 12 microarrays. Data was analyzed using Acuity 4.0 (Molecular Devices Corp., Sunnyvale, CA, USA) and normalized with the LOWESS algorithm [12]. After normalization, data was filtered based on flags, percentage of saturated pixels, background and intensity uniformity, and signal to noise ratio. The logratios of expression were calculated as the base 2 logarithm of the ratios of background-corrected intensity medians of red dye over green dye intensities. A gene was considered to be differentially expressed if it had an absolute value of log-intensity ratio higher or equal to 0.8 , representing a fold-change of 1.7 in transcript quantity. Statistical analysis was performed using the Student's ttest with FDR correction for multiple comparisons [13]. Statistical significance was set at $\mathrm{p}=0.01$. We had previously validated the use of this in-house immune-endocrine bovine microarray with porcine targets [14]. In this study, hybridization resulted in $\sim 90 \%$ positive signals ( 170 features) in agreement with those previous observations. However, the presence of positive signals of hybrid- 


\section{a}

\author{
new allele \\ AF 464037. 1 \\ AB2 15122.1
}

\section{b}

\author{
new allele \\ AB215122. 1 \\ AF 464037.1
}

new allele AB215122. 1 AF 464037.1

new allele AB215122. 1 Aे 464037.1

new allele AB215122. 1 AF 464037.1

new allele AB2 15122.1 AF 464037.1

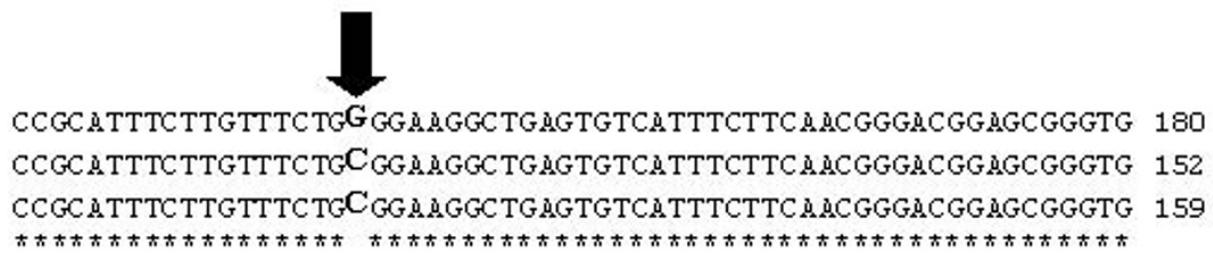

CPLLFSSML HLCFSRGFWMALLTMMLWLSPPL AL ARD TP PHF LFLG KÄCHFFNGTERV 60 ------MLHLCF SRGFWMẢLTMMLWLSPPLAL ÄRD TPPHF LFLRKÄECHFFNGTERV 53

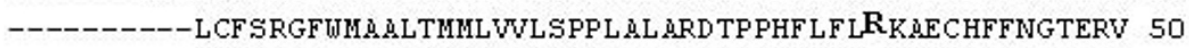

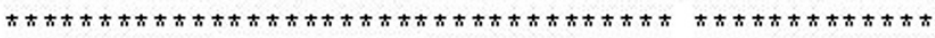

RF LDRYF YNGDE YVRF DSDVGEF REVTEF GRPD AKYTNSQKDF MEQKRAEVD TVCRHNYE 120 RF LDRYF YNGDE YVRF DSDVGEF REVTE F GRPD AKYINSQKDF MEQKR AEVD TVCRHNYE 113 RF LDRYF YNGD EYVRF DSDVGEF REVTEF GRPD AKYWNSQKDF MEQKR A EVD TVCRHNYE 110

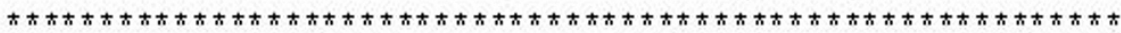

ILETF LVPRR AE PRVTVYP AKTQPLQHHNLLVCSVTGF YP GHVEVRUF RNGQEE DMGVVS 180 ILETF LVPRRAE PRVTVYP AKTQPLQHHNLLVCSVTGF YP GHVEVRUF RNGQE E AMGVVS 173 ILETF LVPRR AE PRVTVYP AKTQP LQHHNL LVCSVTGF YPGHVEVRUF RNGQE E AMGVVS 170

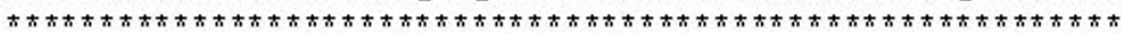

TGLIPNGDWTFQTMVMLE TVPQSGEVYTCRVE HPSLTSPVTVEWRARSESÄQGKMMSGIG 240 TGLIPNGDWTF QTWVMLE TVPQSGEVYTCRVEHPSLTSPVTVEWR HRSES AQGKMMSGIG 233 TGLIPNGDWTFQTMVMLE TVPQSGEVYTCRVEHPSLTSPVTVEWRARSES AQGKMMSGIG 230

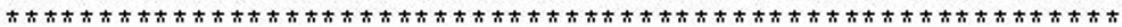

GFVLGLLFV AVGLF I YFKNQKGRP ALQPTGLLS 273 GFVLGLLFV AVGLF I YFKNQKGRP ALQP TGLLS 266 GFVLGLLFV AVGLF I YFKNQKGRP ALQPTGLLS 263

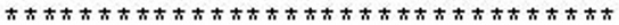

\section{Figure I}

Nucleotide and protein sequence alignment of SLA-DRB I alleles. Multiple sequence alignment for (a) nucleotide and (b) protein of published SLA-DRBI*0403 alleles (designated by their GenBank accession numbers) and *04ns0 (new allele). The black arrows mark (a) the point mutation and (b) the corresponding amino acid residue substitution.

ization does not imply that all spots will provide valid results. As previously mentioned, we performed careful filtering to ensure that only consistent data was subject to further analysis. Results from microarray data analysis are summarized in Table 1 and Figure 2. The *0502 allele group showed higher transcriptional activity for CCL4 and $I L 1 B$ in all comparisons. The *0701 allele group showed less SLA-DQA transcripts in all comparisons. Transcripts amounts for TLR2 and CASP1 were higher in the *0502 and $* 0701$ allele groups respectively, when compared to the ${ }^{*} 04$ ns 01 group. The small number of genes consistently detected as differentially expressed reflects the tendency of heterologous hybridization to reduce the effective size of a given microarray. Although optimal results are obtained with homologous hybridizations, the use of heterologous microarray hybridization is still a valid approach to assess gene expression profiles given that measures are taken to preserve the quality of the data obtained [15]. In addition, results were verified using qPCR as stated in the next section.

Numerous associations have been established in swine between SLA haplotypes and features such as immune response and disease [16,17], reproduction [18] and production traits [19]. Many of these traits are not directly regulated by individual SLA genes but could rather be 

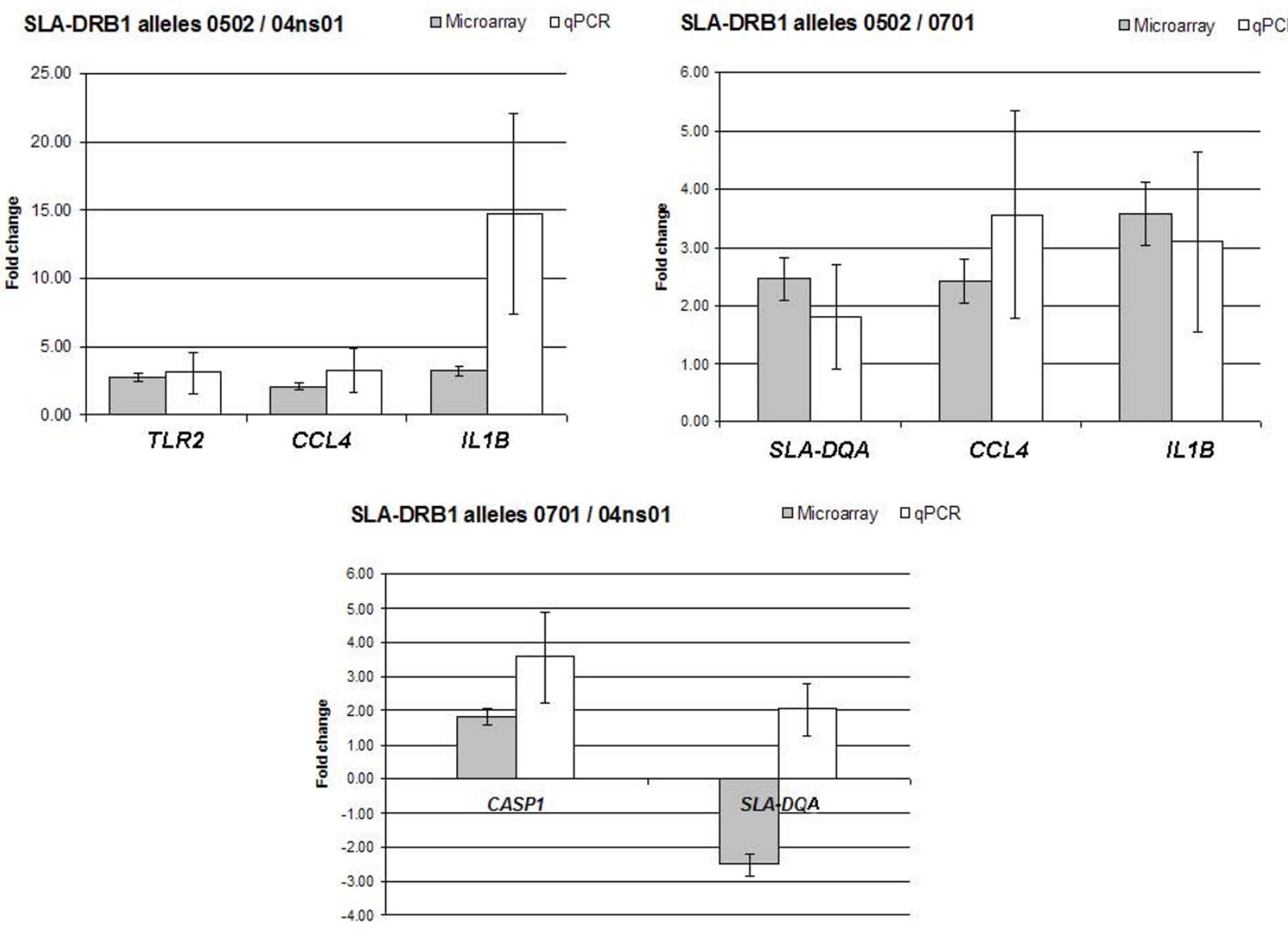

\section{Figure 2}

Differential transcriptional activity detected by cDNA microarray hybridization and qPCR. Mean fold changes in transcript quantification obtained by cDNA microarray hybridization $(\square)$ and qPCR $(\square)$. a) Microarray ( $n=2$ per group) and qPCR (*0502, $\mathrm{n}=9$; *04ns0I, $\mathrm{n}=14$ ) results for the comparison between SLA-DRBI*0502 and *04ns0I. b) Microarray ( $\mathrm{n}=2$ per group) and qPCR (*0502, $\mathrm{n}=9 ; * 070 \mathrm{I}, \mathrm{n}=6$ ) results for the comparison between SLA-DRBI*0502 and *070I alleles. c) Microarray ( $\mathrm{n}=2$ per group) and qPCR (*070I, $\mathrm{n}=6$; $* 04 \mathrm{~ns} 0 \mathrm{I}, \mathrm{n}=\mathrm{I} 4$ ) results for the comparison between SLA-DRBI*070I and $* 04 \mathrm{~ns} 0 \mathrm{I}$.

under the influence of non-classical MHC genes or controlled by downstream pathways yet to be described. The involvement of other closely linked genes, whose variants are in linkage disequilibrium (LD) can not be discarded $[20,21]$. For example, it has been found that differential expression of LTB (also known as TNF beta) in MHC class II-defined B cell lines is associated with certain MHC class II haplotypes but not others. This association could be explained by LD between LTB and MHC haplotypes or by the influence of polymorphism in the MHC class II molecules and their interactions on the control of gene expression [22]. Another example is represented by BRD2 in humans. This transcription factor, without an established immune function and located in the MHC class II region, is strongly linked to the MHC in most vertebrates [23].
Although it is not possible from the results in this study to establish a direct causal relationship between particular SLA-DRB1 alleles and differential transcription of inflammatory genes observed, it is undeniable that there seems to be an association. These observations will be better explained by the characterization of the haplotypes linked to these alleles and further exploration of the immune response in animals with defined MHC haplotypes.

\section{Quantitative RT-PCR}

To verify differential expression observed in the microarray data, qPCR calibrator-normalized relative quantification with efficiency correction in the LightCycler ${ }^{\circledR} 1.5$ system and the Relative Quantification Software v. 1.0 (Roche Diagnostics, Laval, QC, Canada) were used. RPL19 
Table I: Summary of results from cDNA microarray and qPCR data analysis

\begin{tabular}{|c|c|c|c|c|c|c|}
\hline \multirow[b]{2}{*}{ Gene } & \multicolumn{3}{|c|}{ MICROARRAY } & \multicolumn{3}{|c|}{ qPCR } \\
\hline & Fold-change a & Ratiob $^{b}$ & $\mathrm{P}_{\text {-value }}{ }^{\mathrm{c}}$ & Fold-change a & Ratio & $\mathrm{p}$-value \\
\hline \multicolumn{7}{|c|}{ Comparison A: SLA-DRB I alleles 0502/04ns0 I } \\
\hline TLR2 & 2.76 & 1.468 & $<0.0001$ & 3.10 & 1.65 & 0.0586 \\
\hline CCL4 & 2.10 & 1.075 & 0.0010 & 3.27 & 1.71 & 0.2880 \\
\hline ILIB & 3.21 & 1.683 & 0.0025 & 14.72 & 3.88 & 0.0322 \\
\hline \multicolumn{7}{|c|}{ Comparison B: SLA-DRB I alleles 0502/070 I } \\
\hline SLA-DQA & 2.46 & 1.303 & 0.0038 & 1.8 & 0.85 & 0.3569 \\
\hline CCL4 & 2.41 & $1.27 \mid$ & 0.0158 & 3.55 & 1.83 & 0.2926 \\
\hline$I L I B$ & 3.57 & 1.837 & 0.0079 & 3.1 & 1.64 & 0.4168 \\
\hline \multicolumn{7}{|c|}{ Comparison C: SLA-DRB I alleles 070I/04ns0 I } \\
\hline CASPI & 1.79 & 0.840 & 0.0010 & 3.56 & 1.83 & 0.0651 \\
\hline SLA-DQA & -2.52 & -1.335 & 0.0035 & 2.02 & 1.02 & 0.4667 \\
\hline
\end{tabular}

a Fold change $=2$ (Log-ratio) or (-I) 2 (Log-ratio); ${ }^{b}$ Median of the lowess-normalized log-ratio of intensity; ${ }^{~}$ p-value with FDR correction for multiple comparisons.

was tested for variability among samples and selected as reference gene. Specific PCR conditions and primers are described in Table 2. Total RNA samples $\left({ }^{*} 0502, \mathrm{n}=9\right.$; ${ }^{*} 0701, \mathrm{n}=6$ and ${ }^{*} 04 \mathrm{~ns} 01, \mathrm{n}=14$ ) were reverse transcribed using SuperScript III (Invitrogen). The qPCR was performed using LightCycler ${ }^{\circledR}$ FastStart DNA Master SYBR Green I (Roche). Relative standard curves for target and reference genes were created using dilution series with six 10 -fold dilutions in triplicates. One of the dilutions was used as calibrator. Replicate determinations were performed using independent reverse transcription reactions. Results are reported as normalized ratio of target/reference concentrations. Data sets from qPCR were analyzed with a general linear model [24] using the SAS system for Windows v 9 (SAS Institute Inc., Cary NC, USA). A log transformation was used to normalize the data and directly model the ratios of transcript quantification. The ANOVA allowed analysis with unequal variances for CCL4. Statistical significance was set at $\mathrm{p}=0.05$. Results from the qPCR analysis are summarized in Table 2 and Figure 2. In general, qPCR results followed the trend observed by microarray analysis, except for of SLA-DQA, which showed a pattern opposite to the one expected for the ${ }^{*} 0701 /{ }^{*} 04$ ns01 comparison. It appears that differences were more consistent between the ${ }^{*} 04$ ns0 1 and the two other groups, with $I L 1 B$ transcript quantity reaching statistical significance $(\mathrm{p}=0.05)$ and TLR2 $(\mathrm{p}=0.0586)$ and CASP1 ( $\mathrm{p}=0.0651)$ approaching statistical significance, warranting further investigation. It is worth mentioning that lack of statistical significance does not automatically imply lack of biological significance. Analysis of variance components indicated that the individual

Table 2: Gene-specific primers and PCR conditions for relative quantification in the Light Cycler system

\begin{tabular}{|c|c|c|c|c|c|}
\hline Gene name & GenBank $^{\mathrm{a}}$ & Primers $\left(5^{\prime}->3^{\prime}\right) b$ & Prod. size (bp) ${ }^{c}$ & Ann. temp. $\left({ }^{\circ} \mathrm{C}\right)^{d}$ & Acq. temp. $\left({ }^{\circ} \mathrm{C}\right)^{\text {e }}$ \\
\hline \multirow[t]{2}{*}{ TLR2 } & AB085935.1 & F TGCGAATCCTGAAAATAGGC & 343 & 59 & 84 \\
\hline & & R CTTGCGTCAGTGATTTCTGC & & & \\
\hline \multirow[t]{2}{*}{ CCL4 } & NM 001075147 & F GAAGCTCTGCGTGACTGTCC & 391 & 59 & 87 \\
\hline & & R AGGAACAGGATCTGCTGAGG & & & \\
\hline \multirow[t]{2}{*}{ ILIB } & NM 214055.I & F GCAGATGGTGTCTGTCATCG & 444 & 60 & 84 \\
\hline & & R TTCTCCATGTCCCTCTTTGG & & & \\
\hline \multirow[t]{2}{*}{ SLA-DQA } & AY191777.1 & F TGTGGAGGTGAAGACATTGC & 315 & 59 & 83 \\
\hline & & R CAGCATCACTGGAGACTTGG & & & \\
\hline \multirow[t]{2}{*}{ CASPI } & NM 214162.1 & F GAGAAAATCTCACCGCTTCG & 572 & 59 & 83 \\
\hline & & R AGTCACTCTTTCGGCAGTGG & & & \\
\hline \multirow[t]{2}{*}{ RPLI9 } & AV600389 & F ATGAGACCAATGAAATCGCC & 504 & 60 & 87 \\
\hline & & R CATGAGGATCCGCTTGTTTTT & & & \\
\hline
\end{tabular}

a Sequenced used for primer design; b Sequence of forward (F) and reverse (R) primers in 5' to 3' orientation; c Size of the amplified PCR product; ${ }^{\circ}$ Annealing temperature and $\mathrm{e}$ acquisition temperature for qPCR. 
pig ( $p=0.05)$ was an important random effect in transcript quantification. This innate variability of individual pigs is most likely behind the lack of statistical significance in spite of fold-changes higher than 3 being observed. It also points out to the importance of including as many individuals as possible for qPCR confirmation of microarray data, especially individuals that have not been used for the microarray analysis, in order to obtain results that more closely reflect the situation in the population. In the case of CCL4, even though it appeared to be significantly differentially expressed in two of the comparisons (fold change $>3$ ), the differences got lost within the high variability showed by the gene transcript quantifications in the tested groups, indicating that the differences may not be consistent at the population level. This seems to be also the case for differences observed between the *0502 and *0701 allele groups, a fact that suggests that the gene expression profiles of these two groups are not really that distinctive.

\section{List of abbreviations}

LTB, Lymphotoxin beta (TNF superfamily, member 3); BRD2, Bromodomain containing 2; CCL4, Chemokine (C-C motif) ligand 4 ; IL1B, Interleukin 1 beta; SLA-DQA, SLA class II DQ alpha; TLR2, Toll-like receptor 2; CASP1, Caspase 1; RPL19, Ribosomal protein L19, EBI IPD, European Bioinformatics Institute Immuno-Polymorphism Database; BLAST, Basic Local Alignment Search Tool; RTPCR, Reverse transcription - polymerase chain reaction; qPCR, quantitative PCR; SLA, Swine leukocyte antigen; MHC, Major histocompatibility complex; MNCs, Blood mononuclear cells; GEO, Gene Expression Omnibus; MIAME, Minimum information about a microarray experiment; LOWESS, Locally weighted scatter plot smoothing algorithm; FDR, False Discovery Rate.

\section{Competing interests}

The authors declare that they have no competing interests.

\section{Authors' contributions}

MINS participated in the conception and design of the study, carried out the qPCR confirmation, participated in the SLA-DRB1 allele characterization and drafted the manuscript. RJJ carried out the cDNA microarray hybridizations and helped draft the manuscript. BB established the SLA-defined lines of pigs and participated in the characterization of SLA-DRB1 alleles. BAM participated in the design and coordination of the project and helped to draft the manuscript. All authors read and approved the final manuscript.

\section{Acknowledgements}

We wish to acknowledge the financial support of Ontario Pork Producers to BAM and the Government of Iran to RJJ. The assistance of the personnel at Arkell Research Station (University of Guelph), technical support of
Sophia Lim, and assistance in statistical analysis of William Sears are greatly appreciated.

\section{References}

I. Ando A, Chardon P: Gene organization and polymorphism of the swine major histocompatibility complex. Anim Sci J 2006, 77:127-133.

2. Kumanovics A, Takada T, Lindahl KF: Genomic organization of the mammalian MHC. Annu Rev Immunol 2003, 2 I :629-657.

3. Smith DM, Lunney JK, Ho CS, Martens GW, Ando A, Lee JH, Schook L, Renard C, Chardon P: Nomenclature for factors of the swine leukocyte antigen class II system, 2005. Tissue Antigens 2005, 66:623-639.

4. Vaiman M, Chardon P, Rothschild MF: Porcine major histocompatibility complex. Rev Sci Tech 1998, I 7:95-107.

5. Ho CS, Rochelle ES, Martens GW, Schook LB, Smith DM: Characterization of swine leukocyte antigen polymorphism by sequence-based and PCR-SSP methods in Meishan pigs. Immunogenetics 2006, 58:873-882.

6. Lunney JK: Advances in swine biomedical model genomics. Int J Biol Sci 2007, 3: 179-I84.

7. Bridle BW, Wilkie BN, Jevnikar AM, Mallard BA: Rat genotype influences quantitative and qualitative aspects of xenogeneic immune response to pig blood mononuclear cells. Xenotransplantation 2006, 13:299-307.

8. Bridle BW, Wilkie BN, Jevnikar AM, Mallard BA: Deviation of xenogeneic immune response and bystander suppression in rats fed porcine blood mononuclear cells. Transpl Immunol 2007, I 7:262-270.

9. Altschul SF, Gish W, Miller W, Myers EW, Lipman DJ: Basic local alignment search tool. J Mol Biol 1990, 2 I 5:403-4I 0.

10. Thompson JD, Higgins DG, Gibson TJ: CLUSTAL W: improving the sensitivity of progressive multiple sequence alignment through sequence weighting, position-specific gap penalties and weight matrix choice. Nucleic Acids Res 1994, 22:4673-4680.

II. Brazma A, Hingamp P, Quackenbush J, Sherlock G, Spellman P, Stoeckert C, Aach J, Ansorge W, Ball CA, Causton HC, Gaasterland T, Glenisson P, Holstege FC, Kim IF, Markowitz V, Matese JC, Parkinson H, Robinson A, Sarkans U, Schulze-Kremer S, Stewart J, Taylor R, Vilo J, Vingron M: Minimum information about a microarray experiment (MIAME)-toward standards for microarray data. Nat Genet 200I, 29:365-37I.

12. Yang YH, Dudoit S, Luu P, Lin DM, Peng V, Ngai J, Speed TP: Normalization for cDNA microarray data: a robust composite method addressing single and multiple slide systematic variation. Nucleic Acids Res 2002, 30:e I5.

13. Benjamini $Y$, Hochberg $Y$ : Controlling the false discovery rate: a practical and powerful approach to multiple testing. J Roy Statistic Soc Ser B 1995, 57:289-300.

14. Tao W, Mallard B, Karrow N, Bridle B: Construction and application of a bovine immune-endocrine cDNA microarray. Vet Immunol Immunopathol 2004, I 0 I: I-I7.

15. Buckley BA: Comparative environmental genomics in nonmodel species: using heterologous hybridization to DNAbased microarrays. J Exp Biol 2007, 210 :1602-1606.

16. Lumsden JS, Kennedy BW, Mallard BA, Wilkie BN: The influence of the swine major histocompatibility genes on antibody and cell-mediated immune responses to immunization with an aromatic-dependent mutant of Salmonella typhimurium. Can J Vet Res 1993, 57:14-18.

17. Madden KB, Moeller RF Jr., Douglass LW, Goldman T, Lunney JK: Trichinella spiralis: genetic basis and kinetics of the antiencysted muscle larval response in miniature swine. Exp Parasitol 1993, 77:23-35

18. Renard C, Vaiman M: Possible relationships between SLA and porcine reproduction. Reprod Nutr Dev 1989, 29:569-576.

19. Mallard BA, Kennedy BW, Wilkie BN: The effect of swine leukocyte antigen haplotype on birth and weaning weights in miniature pigs and the role of statistical analysis in this estimation. J Anim Sci 1991, 69:559-564.

20. Dorak MT, Shao W, Machulla HK, Lobashevsky ES, Tang J, Park MH, Kaslow RA: Conserved extended haplotypes of the major histocompatibility complex: further characterization. Genes Immun 2006, 7:450-467. 
21. Trowsdale J: HLA genomics in the third millennium. Curr Opin Immunol 2005, 17:498-504.

22. Guo W, Mourad W, Charron D, Al Daccak R: Ligation of MHC class II molecules differentially upregulates TNF beta gene expression in B cell lines of different MHC class II haplotypes. Hum Immunol 1999, 60:312-322.

23. Shiina $T$, Inoko $H$, Kulski JK: An update of the HLA genomic region, locus information and disease associations: 2004. Tissue Antigens 2004, 64:63I-649.

24. Littell RC, Milliken GA, Stroup WW, Wolfinger RD: SAS System for Mixed Models Edited by: Inc. SASI. Cary, NC, USA; 1996-656.

Publish with Bio Med Central and every scientist can read your work free of charge

"BioMed Central will be the most significant development for disseminating the results of biomedical research in our lifetime. "

Sir Paul Nurse, Cancer Research UK

Your research papers will be:

- available free of charge to the entire biomedical community

- peer reviewed and published immediately upon acceptance

- cited in PubMed and archived on PubMed Central

- yours - you keep the copyright

Submit your manuscript here:

http://www.biomedcentral.com/info/publishing_adv.asp 